\title{
Educar en valores a través de un club de lectura escolar: un estudio de caso
}

\section{Educate in values through a school book club: a case study}

\author{
Carmen ÁLVAREZ ÁLVAREZ y Raquel GUTIÉRREZ SEBASTIÁN \\ Universidad de Cantabria
}

Recibido: Mayo 2012

Aceptado: Julio 2012

\begin{abstract}
Resumen
Los Clubs de Lectura son espacios de encuentro entre diferentes personas que comparten lecturas. En el ámbito escolar, han ido proliferando poco a poco, consiguiendo iniciar, potenciar y/o afianzar el hábito lector en la infancia, además de mejorar la competencia lectora y promover la educación en valores del alumnado. En el artículo se recoge una investigación sobre un club de lectura escolar concreto en el que se ha hecho hincapié en la última cuestión referida. El artículo ofrece las principales conclusiones al respecto, destacando la importancia de la formación de los coordinadores de los clubs de lectura para ligar la formación lectora y la ciudadana.
\end{abstract}

Palabras clave: Club de Lectura, educación en valores, estudio de caso, competencia lectora.

\section{Abstract}

The Book Clubs are spaces of meeting between different persons who share readings. In the school, they have been proliferating, managing to initiate, to promote and/or to guarantee the reading habit in the infancy, beside improving the reading competition and promoting the education in values of the students. In the article a research is gathered on a concrete club of school reading in the one that has been emphasized in the last above-mentioned question. The article offers the principal conclusions in the matter, emphasizing the importance of the formation of the coordinators of the clubs of reading to tie the reading formation and the citizen. Keywords:Book Club, education in values, case study, reading competence.

Las investigaciones que han abordado el análisis de los clubes de lectura estiman que los primeros se iniciaron en el ámbito anglosajónen la época victoriana. La principal razón que los ha hecho perdurar hasta nuestros días ha sido su enorme capacidad para favorecer el gusto por la lectura, mejorar la competencia literariaydesarrollar hábitos lectores en los participantes. Pese a las notables diferencias que existen hoy en día entre las múltiples experiencias de clubs de lectura desarrolladas, tanto en el panorama nacional como en el internacional, los estudios 
realizados han venido destacando una y otra vez sus enormes posibilidades en la creación, desarrollo y potenciación del hábito lector (Calvo, 2007; Aranda y Galindo, 2009).

Los primeros clubs de lectura en España surgieron a mediados de los años ochenta y se han desarrollado en bibliotecas públicas, dirigiéndose mayoritariamente a personas adultas (Mata, 2009: 82) y las primeras investigaciones dedicadas a ellos se remontan a los años noventa. En toda la investigación desarrollada al respecto se comprobó una y otra vez el éxito de los clubs de lectura para contribuir a desarrollar hábitos lectores. La positiva valoración recibida por los implicados en los mismos (bibliotecarios y usuarios, generalmente) ha generado un contexto favorable, propicio a que los mismos fueran creciendo y diversificándose con el paso del tiempo, hasta el punto de que se han creado clubs de lectura en otros marcos espaciales y temporales diferentes a los inicialmente planteados: escuelas de adultos, centros educativos de Educación Infantil y Primaria, centros penitenciarios, asociaciones, empresas privadas, etc., estos se han ocupado de temáticas generales o especializadas y han tenido carácter presencial o virtual (Domingo y Sola, 2005).

Un club de lectura bien organizado presenta una serie de elementos entre los que podemos señalar como más pertinentes el proceso de argumentación y consenso que se sigue para la selección de la obra objeto de lectura, que inicialmente solía ser propuesta por el bibliotecario como experto, pero que en la actualidad suele surgir del acuerdo de los participantes, la lectura generalmente individual de la misma y el comentario conjunto entre los socios del club en una o varias reuniones específicamente pactadas para tal fin. Mata (2009: 82) ha escrito: “frente a la lectura solitaria, íntima y silenciosa, que es en este tiempo, la modalidad más habitual de lectura, surgen aquí y allá espacios de encuentro de lectores unidos por la voluntad de hablar de libros. Eso es, en esencia, un club de lectura: una ocasión de leer con los demás, un deseo de compartir lecturas, un modo dialogal de extender la mirada y afinar los oídos”.

Con el paso del tiempo los clubs de lectura han ido saliendo de las bibliotecas, diversificándose, y propiciando el desarrollo del hábito lector en personas de todas las edades y en todos los contextos, especialmente los educativos. Así, por ejemplo, cabe destacar los clubs de lectura llevados a cabo en el ámbito universitario, como asignaturas transversales, o una variante muy interesante, en la que nos detendremos, que son los clubs de lectura escolares, que se proponen favorecer el gusto de la infancia y/o sus familias por la literatura, desde la escuela y especialmente, desde su biblioteca. Los clubs de lectura desarrollados en las diferentes escuelas españolas se caracterizan por su enorme diversidad: edad/es a las que se dirigen, participación o no de familias, selección de las obras, tiempos dirigidos a reunirse, etc. En función de la ambición del proyecto, la formación de los mediadores, la implicación del profesorado, el interés de la escuela, etc. caben muchas posibilidades. Algunas de las experiencias más destacadas de estos clubs de lectura escolares realizadas en el marco de la Educación Primaria y Secundaria se encuentran recogidas en Mata (2009: 82-85). Muchas de ellas, además, están disponibles en la red, a través de páginas web, blogs y otros sistemas virtuales, que contribuyen a difundir la amplia tarea de animación a la lectura 
y fomento de la competencia lectora que se está haciendo actualmente desde algunos centros.

La investigación sobre el valor de la lectura, los hábitos lectores y el contacto con los libros en el tiempo de ocio desarrollada por Yubero y Larrañaga (2010)en la Educación Primaria, con una muestra de 1669 estudiantes de Educación Primaria (847 niños y 822 niñas), revela que el valor de la lectura varía en función del comportamiento lector y de los hábitos de lectura, que las chicas informan de niveles más altos de lectura que los chicos y que en ambos casos, en chicos y chicas, sus hábitos lectores se correlacionan con los hábitos lectores de sus familiares próximos. Los clubs de lectura escolares constituyen una innovación educativa que contribuye a la adquisición o desarrollo de valores positivos hacia la lectura, estimular el hábito lector y a desarrollar el gusto por la lectura en el tiempo de ocio (Álvarez, 2010, 2011).

Una definición sintética y acertada del concepto de club de lectura escolar es la aportada por Lage (2006: 96), quien lo ha definido como "el encuentro o reunión entre alumnos que muestran interés por comentar un libro o compartir diferencias experiencias lectoras. Básicamente se trata de una tertulia literaria, de un intercambio de opiniones". En algunos centros también se han creado varios clubs de lectura: para personas adultas (familiares y maestros, generalmente) y para niños (Álvarez, 2010) o han participado personas adultas en los clubs dirigidos a la infancia (Peña y Barboza, 2002).

En todo caso, los clubs de lectura escolares suelen seguir unas formas habituales: se selecciona un libro, se determina un tiempo para su lectura y se fija una reunión posterior para proceder a comentar la obra. En estas reuniones se suelen abordar pasajes destacados del libro, se cuestionan comportamientos de los protagonistas, se plantean experiencias personales, se ofrecen pensamientos y reflexiones, etc. generándose un intercambio rico entre los participantes. Al tratarse de clubs de lectura a realizar con niños en el entorno escolar, en todas las investigaciones se destaca la figura del mediador o animador a la lectura (Tejerina, 1997, 2008; Coronas, 2005; Cerrillo, 2005, 2007; Chambers, 2007; Mata, 2009), de la calidad del diálogo generado en las reuniones de lectores (Pennac, 1993; Navarro, 2000; Chambers, 2007) así como de la biblioteca escolar (Bartolomé, 1999; Lage, 2006; Patte, 2008; Mantilla, 2009; Durban, 2010).

Todos los clubs de lectura escolares comparten las mismas notas características que definen al resto de clubs (ya sean realizados en otros marcos espacio-temporales como asociaciones, prisiones, empresas... o exclusivamente con personas adultas), en tanto que pretenden desarrollar el gusto por la lectura y el hábito lector, pero indudablemente, persiguen otros fines, dado que los clubs de lectura escolares tienen un marcado carácter educativo. Las finalidades fundamentales que se persiguen con un club de lectura escolar, en conexión con los objetivos del curriculum escolar de la etapa de Educación Primaria y los Proyectos Lectores de centro, son: 
- Finalidad lingüística: mejorar la competencia lectora, es decir, la comprensión lectora, la velocidad, el enriquecimiento léxico, etc. (Cerrillo y García, 1996; Chambers, 2007).

- Finalidad literaria: despertar, desarrollar o potenciar la relación infancia-libro, aproximando a los niños algunas de las mejores obras de literatura infantil y juvenil para su disfrute (Lage, 2006; Lockwood, 2008).

- Finalidad educativa: desarrollar el gusto por la lectura y el hábito lector favoreciendo en todo momento una lectura crítica (Cassany, 2002; Atwell, 2007; Carratalá, 2008; Jurado, 2008; Tejerina, 2008).

- Finalidad cívica y social: favorecer la educación en valores del alumnado y mejorar la comunicación y las relaciones interpersonales entre los estudiantes(Sánchez y Yubero, 2004).

En la investigación que sustenta este trabajo nuestro objetivo ha sido analizar cómo se pueden favorecer estas cuatro finalidades deseadas en un club de lectura escolar, en línea con las aportaciones teóricas actuales de la didáctica de la lengua y la literatura desarrolladas por Cerrillo, Cassany, Chambers, Lage, Tejerina, Sánchez y Yubero, entre otros, para lo cual llevamos a cabo una investigación durante un curso académico, siguiendo el desarrollo de un club de lectura escolar concreto, en el marco de la Educación Primaria. Nos centraremos, no obstante en las dos últimas finalidades, la educativa y la cívica social, pues la exploración de todas las dimensiones señaladas implicaría el desarrollo de un trabajo cuyos límites pueden resultar excesivos, y porque además, estas dos constituyen por sí mismas un campo con interés, en tanto que vinculan dos grandes campos: el de la literatura y el de la formación ciudadana, relacionando el proceso de lectura y de construcción de valores. En este sentido estamos de acuerdo con lo afirmado por Abril (2000: 7): “el fenómeno de leer para discutir y discutir para conocerse evidencia tanto la necesidad de cohesión social como ofrece la posibilidad de favorecer la convivencia".

Algunas investigaciones realizadas desde la pedagogía sobre educación en valores (dentro y fuera del marco escolar) apuntan que la lectura puede ser una aliada en el proceso de formación del sujeto (Puig Rovira, 1995; Buxarrais, 1997; Camps y otros, 1998; Navarro, 2000; Escámez, 2003; Martínez y Hoyos, 2006; Bolívar, 2007). Los Observatorios de la convivencia escolar plantean incesantemente entre sus objetivos la necesidad de fomentar la lectura en tiempo de ocio, favorecer la participación familiar en los centros escolares, la prevención del acoso escolar, etc. También hay investigaciones desde la literatura que manifiestan cómo la lectura contribuye a desarrollar a los sujetos desde el punto de vista axiológico, destacándose al respecto, generalmente, la relevancia de propiciar un proceso de diálogo sobre las lecturas realizadas (Chambers, 2007; Patte, 2008; Gutiérrez y Rodríguez, 2008; Tejerina, 2008; Martos y Rösing, 2009; Mata, 2009; Meyer, 2010). Como afirma García (2005: 47), hoy día la escuela reconoce y fomenta las posibilidades de la literatura infantil para una verdadera formación integral de los alumnos. 
El Grupo de Investigación en Educación Moral de la Universidad de Barcelona (GREM), tomando distancia con paradigmas caducos ha planteado una línea teórica sobre educación en valores que seguimos: el "modelo de construcción racional y autónoma de valores” (Buxarrais, Martínez, Puig y Trilla, 1995). Este enfoque supera las limitaciones del "modelo de valores absolutos" que considera que existen una serie de valores indiscutibles e inmodificables que deben acatarse y que se tienen que transmitir costumbres y normas (generalmente con el apoyo de algún poder autoritario), sin tener en cuenta los procesos de pensamiento de los alumnos. También supera el "modelo de valores relativos", opuesto al indicado, que aprovechando la crisis del modelo anterior, considera que no hay ninguna opción de valor preferible en sí misma a las demás, sino que, en realidad, valorar algo es una decisión que se basa en criterios totalmente subjetivos. Por tanto, nada es en puridad bueno o malo, sino que depende de las circunstancias, condiciones o momentos en que cada cual enjuicia la realidad. Bajo estas claves, como resulta lógico, este modelo limita el papel otorgado a la educación en valores, pues no hay nada que enseñar: las decisiones son cuestiones individuales y los valores se aprenden de modo espontáneo.

Actualmente las principales investigaciones sobre valores se apoyan en el modelo de construcción racional y autónoma, que no defiende ni unos determinados valores absolutos ni pretende situarlos a un mismo nivel. Desde este modelo se afirma que no todo es igualmente bueno, y que hay posibilidades en la razón, el diálogo y la ilusión por determinar algunos principios valiosos de carácter abstracto y universal que pueden servir de guías de la conducta social, en el marco de una sociedad democrática, abierta y plural en la que los seres humanos son considerados como autónomos, libres e iguales en dignidad y derechos.

Este modelo defiende la posibilidad de usar libre y autónomamente la razón para elaborar criterios que servirán de referente a las normas de conducta. "Desde la perspectiva pedagógica, puede decirse que estamos ante una educación moral de mínimos; una educación moral que, mediante el diálogo, la reflexión, la empatía y la autorregulación, quiere ser capaz de facilitar la construcción de unos principios que sean universalmente aceptables, y que permitan no sólo regular la propia conducta, sino también construir autónomamente las formas de vida concretas que en cada situación se consideren, además de justas, mejores y más apropiadas” (Buxarrais, Martínez, Puig y Trilla, 1995: 20).

En consecuencia, se promueve un modelo de valores elaborado a partir de la toma de conciencia respecto a la conveniencia de ciertas opciones frente a otras, el cual debe ser construido a través de espacios abiertos para la reflexión, el análisis crítico, la discusión y el intercambio de ideas sobre los principios de valor que pueden servir posteriormente como criterios para guiar el comportamiento en situaciones concretas.

A través de este modelo se pretende lograr el desarrollo de las siguientes dimensiones de la personalidad moral: autoconocimiento, autonomía, autorregulación, capacidad de diálogo, capacidad para transformar el entorno, comprensión crítica, empatía y perspectiva social, habilidades sociales y para la convivencia, razonamiento 
moral, etc. sobre la base de la autonomía de la conciencia de los seres humanos, como producto de las relaciones de igualdad entre los individuos y las relaciones dialógicas.

Como puede apreciarse, discrepa del modelo de valores absolutos en el grado de autonomía que tiene el sujeto para construir sus procesos valorativos y normas morales a través del ejercicio de una racionalidad comunicativa. A su vez, también se distancia del modelo de valores relativos al reconocer que a través de la razón y el diálogo es posible fundamentar ciertos principios y valores universales.

En este sentido, un club de lectura escolar constituye un marco excepcional para favorecer la educación en valores, en tanto que los niños se están poniendo en contacto con los valores que muestran las obras y con la interpretación que dan a las mismas sus compañeros y las personas adultas que estén implicadas en el club: hablando y pensando a partir de una misma lectura (Lynch, 2009; Blum y otros, 2010). El proceso, esquemáticamente, podríamos decir que es el siguiente:

Valores en la infancia $\rightarrow$ Puesta en relación con los valores implícitos y explícitos de la obra (generalmente los autores de literatura infantil y juvenil, a través de las acciones de los protagonistas del libro tratan de modelar la conducta del lector) $\rightarrow$ Afirmación/modificación de valores $\rightarrow$ Crecimiento axiológico infantil $\rightarrow$ Puesta en relación de los nuevos valores del niño con la interpretación que hace un grupo de iguales y personas adultas (mediadores, familiares, etc.)sobre los valores de la obra $\rightarrow$ Afirmación/modificación de valores $\rightarrow$ Nuevo crecimiento axiológico en el niño.

Imagen 1. Proceso de construcción de valores en un club de lectura escolar. (Elaboración propia).

Hoy día está aceptado que todos los temas tienen interés para la infancia sin son tratados a un nivel que los niños lo puedan entender (Tejerina, 1997: 281; Patte, 2008: 110). Los textos literarios dirigidos a la infancia, de una u otra manera, suelen cumplir una función ejemplarizante, proponiendo modelos positivos o negativos de conducta, “casos que pueden servir de ejemplos o contraejemplos" (Senís, 2006: 85). En todo caso, hay una amplia diversidad literaria en lo relativo a valores:

- Libros clásicos, libros de autores clásicos y clásicos adaptados, que generalmente están plagados de valores. Como plantea Tejerina (2008: 67), “la gran literatura aporta valores (...), los buenos libros hacen interrogarse”.

- Libros con clara función moralizante, creados específicamente para abordar un tema controvertido (la homosexualidad, el maltrato, las adopciones, etc.). Esta literatura transversal, para Tejerina (2008: 68), no siempre logra sus objetivos, en tanto que el tratamiento de los temas se hace de modo "forzado y adoctrinante". 
- El resto de libros. También incorporan valores, implícitos o explícitos. En todo caso, como plantea Mata (2009: 115), "la lectura lleva a emitir juicios morales".

En vista de esto, con cualquier tipo de libro, un club de lectura escolar, puede contribuir a potenciar la elaboración de juicios valorativos en sus tertulias: "necesitamos enseñar a analizar sin restricciones una obra, elaborar juicios críticos perspicaces, realizar inferencias, hacer valoraciones éticas” (Mata, 2009: 184). Si bien en el proceso de lectura individual los niños se suelen identificar con los protagonistas de las aventuras literarias (Patte, 2008: 78), en el proceso de lectura colectivo, en la tertulia, tienen la oportunidad de tomar la palabra y aportar sus valores a la lectura (Cerrillo y García, 1996: 17; Peña y Barboza, 2002: 170; Chambers, 2007: 22). Como ha afirmado Ostria (2005: 8), “aprender a leer es aprender a construir los sentidos posibles entre varios y aprender a confrontar sus construcciones con las de otros”. Así se educan el sentido estético, la dimensión ética y las emociones (Camps, 2011).

\section{Metodología}

Puede investigarse el aporte que hace un club de lectura escolar a la formación en valores del alumnado de muchas formas. En nuestro caso hemos realizado un estudio de caso en un club de lectura escolar de un centro público de una ciudad española siguiendo un proceso de investigación-acción liderado por una de las autoras de este artículo, con un proceso sistemático de recogida de datos. La potencialidad más grande de este método de investigación, el estudio de caso, es sin duda, la de ofrecer la posibilidad de conocer profundamente una realidad educativa para comprenderla y así, tratar de mejorarla (Álvarez y San Fabián, 2012), lo que a su vez, puede ser de utilidad para otros casos, ya sean éstos más o menos afines. Para ello se elige una muestra pequeña (un caso o varios), pero significativa (relevante, con interés) y se profundiza en él mediante técnicas de recogida de información variadas (tanto cuantitativas como cualitativas), que garanticen el rigor (triangulación, saturación, etc.). La potencia y justificación investigadora de un estudio de caso se basa en el supuesto de que lo global se refleja en lo local, es decir, en la naturaleza holográfica de la realidad, describiendo cualquier proceso de una unidad de vida en sus diversas interrelaciones con su escenario cultural.

En el curso en el que se llevó a cabo la investigación (el curso 2009-2010) intervinieron en el mismo 25 alumnos y alumnas de tercer ciclo: 10 niños y 15 niñas y se leyeron cinco libros de literatura infantil y juvenil seleccionados por los coordinadores atendiendo a criterios didácticos y literarios. Los coordinadores durante ese curso fueron una profesora universitaria externa al centro (que previamente había desarrollado en él su tesis doctoral) y un alumno de la Facultad de Pedagogía. La profesora universitaria había participado en ediciones anteriores del club de lectura (primero como participante y en los dos años siguientes en calidad de coordinadora 
colaborando con un profesor del centro). El reto de afrontar la coordinación del club de lectura escolar citado en toda su responsabilidad supuso un estímulo para el desarrollo de un proceso de investigación-acción ligado a su propio trabajo.

La investigación-acción tiene un especial interés por su concepción del docente como un investigador, y presenta enfoques y experiencias muy variadas, y en algunos casos, contradictorias (Stenhouse, 1987; Kemmis, 1992; Elliot, 1993; Carr, 2007; Whitehead, 2009). En nuestro caso, entendemos la investigación-acción como una metodología de investigación cuyo interés es conocer y entender los problemas cotidianos reales que vive el profesorado, con el objetivo de analizar la propia práctica para conocerla, comprenderla y tratar de transformarla y mejorarla, desarrollándose así profesionalmente el profesorado, que se va emancipando a medida que va llevando a efecto estos procesos.

La experiencia del club de lectura escolar del caso objeto de estudio se inició en el curso 2003-2004, creándose un club para familias en el que se implicaron también algunos profesores del centro. Desde el curso 2006-2007 hubo además interés por parte de un importante número de alumnos de crear un club de lectura para ellos también, consolidándose desde este curso dos clubes de lectura diferenciados: uno para adultos y otro para alumnado del tercer ciclo de Educación Primaria.

En el club de lectura estábamos seguros de que muchos aspectos eran susceptibles de mejora, de modo que nos propusimos hacer un trabajo de revisión de la práctica sistematizado en soporte escrito para dar mayor rigor a las observaciones que habíamos ido anotando y a través de las que podíamos dar cuenta de las ideas que manejábamos previamente a cada reunión de planificación, durante la misma, en el proceso de acción y tras ésta, en la reflexión.

El objetivo general de la investigación ha sido profundizar en el conocimiento del proceso del Club de Lectura a lo largo del curso y favorecer, en este marco, nuestro propio crecimiento profesional como docentes. Para ello llevamos a cabo diferentes estrategias a lo largo de todo el curso en el que implementamos la investigación sobre la innovación, dirigidas sobre todo a registrar las reuniones mantenidas (en el curso investigado se realizaron seis reuniones del Club de Lectura de entre 55 y 70 minutos de duración cada una: una de presentación y cinco más dirigidas a comentar los cinco libros seleccionados). En estas reuniones se explicaban en un primer momento cuestiones organizativas que afectaban a las reuniones. Seguidamente se abría una ronda de intervenciones (dando la palabra a todas las personas que la pidieran) para opinar sobre la lectura, procurando que ésta fuera seguida de razones y argumentos. Tras ella, se abría otra ronda para destacar los momentos más destacados/curiosos/interesantes del libro, participando el alumnado muy activamente. Finalmente se abría otra ronda de intervenciones para participar estableciendo relaciones entre el contenido del libro y la vida cotidiana. La reunión concluía con el sorteo de un ejemplar del libro leído entre los participantes.

En el proceso de investigación hemos generado variados documentos escritos (trascripciones, correos electrónicos, notas diversas), grabaciones en audio de todas las reuniones y en vídeo de dos de ellas, notas de campo durante y a posteriori de cada 
sesión y una memoria exhaustiva donde damos cuenta de la planificación, acción y reflexión realizada a partir de cada reunión del Club con el objeto de registrar el máximo caudal de información, triangular y saturar todos los datos registrados en los diferentes soportes. También hemos contado con observadores externos puntuales que nos han ayudado a pensar sobre esta actividad con los que hemos tratado de reflexionar sobre las ideas y prácticas expuestas. Cada uno de ellos ha ofrecido su propia visión del proceso innovador desarrollado, contribuyendo a su mejora.

Con posterioridad a todo ello se procedió a organizar el abundante caudal de datos cualitativos recogidos y a su análisis, siguiendo pautas propias del análisis de contenido.

\begin{tabular}{|l|}
\hline Guión del trabajo de investigación \\
\hline Planificación (de cada reunión) \\
\hline Acción (las reuniones, propiamente) \\
\hline Reflexión (las ideas manejadas sobre la acción, durante y después) \\
\hline Metarreflexión (valoración final del trabajo) \\
\hline
\end{tabular}

Tabla 1. Proceso seguido en la sistematización de la investigación-acción.

En este artículo nos centraremos en el examen de uno de los objetivos del club de lectura: la educación en valores del alumnado participante, en coherencia con uno de los objetivos de la investigación, que comentaremos a continuación: conocer cómo se puede educar en valores a través de un club de lectura escolar.

Nuestra hipótesis de partida puede resumirse en los siguientes términos: “un club de lectura puede contribuir a la educación en valores del alumnado participante a través de la puesta en relación de los valores del lector y los valores que transmite la lectura en solitario de la obra y de la puesta en relación de los valores de la obra y de los compañeros, expuestas en las tertulias que se hacen”.

\section{Estudio de caso: la educación en valores en nuestro club de lectura escolar}

En el club de alumnos los coordinadores han apostado por trabajar especialmente temas de interculturalidad y de mejora de la convivencia de manera explícita para favorecer la educación en valores del alumnado, a través de las lecturas seleccionadas. (Aunque en el club de adultos también han surgido en ocasiones debates sobre asuntos vinculados a estas cuestiones, no nos detendremos en él). En todo caso, el centro puede ser considerado un colegio propiamente multicultural, dado que cuenta con un $25 \%$ de alumnado inmigrante (como se manifiesta en la investigación desarrollada en este centro por Louzao, 2011). 
Una de las lecturas realizada en el curso en que se desarrolló la investigación fue ¡No es tan fácil ser niño!, de Pilar Lozano Carbayo, en el cual se narra la historia de un alumno convencional que de repente, al ser cambiado de clase, pasa a ser marginado por sus compañeros, iniciándose así una historia enternecedora sobre el acoso escolar. Nos pareció que sería un libro interesante para tratar temas de convivencia y conflicto escolar, que sin duda, pone de manifiesto la sensibilidad de su autora con un problema social relevante: las relaciones de convivencia y conflicto que se dan entre el alumnado en los centros educativos.

Otro de los libros seleccionados fue Luna de Senegal, de Agustín Fernández Paz. En él, Khoedi, la niña protagonista de la historia, narra su viaje de Senegal a España, viniendo a reencontrarse con su padre tras muchos años sin verse, desde que él emigró ilegalmente, desvelando la historia las principales penurias por las que puede pasar un extranjero en nuestro país tratando de sobrevivir. El texto, al igual que el anterior, manifiesta un alto grado de compromiso social y coraje en el autor, al plantear abiertamente un debate social tan duro como lo es la inmigración ilegal, atreviéndose a narrar la historia en primera persona, planteando las principales problemáticas de la inmigración (a nivel personal, laboral, legal, lingüístico, sentimental, etc.) abriendo al lector sus perspectivas de análisis sobre valores como la tolerancia, el respeto, la interculturalidad o el amor.

Antes de leerlos, cada niño partía de una situación axiológica diferente (cada alumno tiene sus propias ideas sobre la inmigración o la convivencia). Las lecturas, en sus diversos pasajes han proporcionado a los estudiantes momentos de reflexión de interés que han llevado a afirmar/modificar valores, provocando un crecimiento axiológico. En las reuniones mensuales del Club de Lectura, al hablar sobre las lecturas entre el alumnado y los coordinadores participantes, se produce un nuevo estímulo en el desarrollo de valores: los estudiantes analizan oralmente las obras (opinan sobre ellas, destacan momentos, enjuician los mensajes que transmiten, etc.), produciéndose un aprendizaje dialógico. Así, podríamos decir que en las reuniones organizadas para comentar las lecturas realizadas se consigue el máximo desarrollo axiológico del niño a través de la metodología dialógica. Por esta razón, el objeto de este apartado es explicar algunos de estos momentos vividos en las reuniones dirigidas a comentar los dos libros mencionados a partir de la trascripción de momentos de debate sobre convivencia e interculturalidad.

A continuación reproducimos un breve fragmento de conversación comentando el libro ¡No es tan fácil ser niño! (comentando las páginas 22-24):

- Coordinador. Cuando Fernando tenía problemas, ¿qué opináis de que no contaba nada a su padre ni a su madre? ¿Quién me cuenta algo sobre el tema?

- Alumna. A mí eso no me parece bien porque a mí si me pasa algo yo siempre se lo cuento a mis padres.

- Alumna. Eso está muy mal porque si tú se lo cuentas a tus padres te podían ayudar diciéndoselo al director o al profesor. 
- Alumna. Yo se lo contaría porque a lo mejor te pueden ayudar a resolverlo y si te lo callas pues empeora.

- Coordinadora. Los padres normalmente son personas que nos quieren y que tienen más experiencia en la vida y que nos pueden ayudar desde puntos que no sospechamos.

En este fragmento, a partir de la pregunta del coordinador acerca de las ventajas de compartir un problema con las personas cercanas (la familia) se inicia un proceso de reflexión sobre la importancia de hacer lo contrario que el libro "enseña" a partir de la conducta del protagonista, que nunca cuenta nada a sus padres ni a nadie sobre el acoso que vive. Así, los niños se paran a pensar en ese acontecimiento y llegan a la conclusión de que es mejor hablar las cosas.

Con esta lectura se abordaron muchos temas: las burlas en clase y fuera de ella, los sentimientos de la persona acosada, el miedo a contarlo a los demás, las razones del acoso, el papel de la violencia en la resolución de este tipo de conflictos, etc.

Reproducimos ahora otro breve fragmento de conversación comentando ese mismo libro (páginas 100-120).

- Coordinador. ¿Por qué Pedrito Lucendo deja de meterse con Fernando? [...] ¿Por qué de repente parece que ya, que se acabó?

- Alumna. Porque ahora nadie le ríe sus gracias.

- Coordinador. Claro. Exactamente. Ya nadie le ríe las gracias. Ya no es el centro de atención. Ya no tiene el corrillo que todo se lo reía y le consideraba el centro de atención. Cuando alguien se ríe de algún compañero, ¿qué pensáis que tenéis que hacer?

- Alumna. Decirle al compañero que se está metiendo con el otro que pare, que no tiene gracia y que deje de meterse con él.

- Coordinadora. ¿Tú eso lo has hecho muchas veces?

- Alumna. No.

[Risas]

- Coordinadora. ¿A partir de ahora te lo vas a pensar?

- Alumna. Sí.

- Coordinadora. ¿Te sirvió para algo la lectura?

- Alumna. Sí.

En este fragmento se somete a cuestión otro hecho que aparece recogido implícitamente en el libro: el acoso escolar existe porque hay personas que ríen las 
gracias de la persona maltratadora. Al analizarlo grupalmente, el alumnado toma conciencia de esta cuestión y además, a partir de la intervención de la coordinadora, una niña reconoce públicamente que el consejo que da, no se lo está aplicando a sí misma, lo que la lleva a reconocer públicamente un frente abierto de mejora, comprometiéndose con la docente a pensarse de ahora en adelante su papel en la reproducción del ciclo de la violencia.

En la tertulia de Luna de Senegal se produjeron momentos importantes de reflexión sobre la inmigración. Se explicaron las diversas dificultades por la que atraviesa un inmigrante, tanto el "legal” (la niña) como el "ilegal” (el caso de su padre). En el siguiente fragmento es posible ver algunas de las ideas analizadas (páginas 119-125).

- Alumno. Tuvieron que salir de la barca para ir nadando para que no les encontrara la policía que estaban registrando las playas.[...] Luego consiguió escapar porque le recogió una chica que iba en coche para salvarle.

$[\ldots]$

- Coordinadora. ¿Qué papel os parece que juega esa chica dentro del libro? ¿Por qué creéis que el autor mete a esa chica que le ayuda en el libro? Los autores cuando escriben los libros tienen una intención, normalmente. Y si escriben libros de literatura infantil tienen casi seguro, casi seguro, la intención de educar a quienes se van a leer el libro. ¿Qué mensaje creéis que os quiere trasmitir el autor?

- Alumno. Que hay que ayudar a la gente.

En este pasaje, a partir del momento de la obra que destaca el niño, la coordinadora trata de despertar en él el espíritu crítico en el alumno interrogándole por el sentido que tiene que en la historia aparezca una persona que ayuda al inmigrante.

A continuación reproducimos otro breve fragmento de nuestra tertulia donde hablamos de la dureza de la inmigración ilegal (páginas 119-125).

- Coordinadora. Os voy a leer un trocito del libro que a mí me impresionó mucho. Es cuando va viajando el padre en el cayuco y lo cuenta en la cena que celebran con sus amigos senegaleses. Les dice a los que estaban en la mesa, en la tertulia: "Un viaje de más de mil kilómetros, en un barco tan cargado de gente que ni se podían mover. Casi sin agua y sin comida, sin tener siquiera espacio para tumbarse, durante cinco días eternos, con el mar y el cielo como único paisaje. Al tercer día empezamos a ver un montón de cadáveres flotando en el agua, personas como nosotros arrastradas por las corrientes: hombres la mayoría, pero también mujeres y algún niño. Un poco más allá descubrimos los restos de otro cayuco semejante al nuestro. Algún golpe de mar parecía haberlo tronzado por la mitad. Paramos el motor y dimos varias vueltas por la zona para ver si había supervivientes, pero no encontramos a nadie vivo. Podríamos haber sido nosotros los ahogados. 
Nuestra embarcación no era mejor. A estas horas podríamos estar en el fondo del mar”. ¿Qué os parece esto que os acabo de leer? ¿Os da algo que pensar?

- Alumno. Mucho.

- Coordinadora. ¿Cómo la gente se juega sus vidas para venir a España pensando que se van a encontrar algo mejor? ¿Qué te da que pensar a ti que dices que te da que pensar mucho?

- Alumno. No sé, que es jugarte la vida, que te puede salir bien o salirte mal, lo que yo pienso.

- Coordinador. [...] ¿Vosotros habíais pensado alguna vez por lo que habían pasado personas de Senegal para llegar aquí?

- Alumno. Yo pensé que cómo se pueden arriesgar a dejar el país y pasar por esto.

- Coordinadora. ¿A ti te parece de valientes abandonar el propio país para ir a otro sitio, sin saber lo que te vas a encontrar, sabiendo que se pueden ahogar...?

- Alumno. Sí, y sin saber el idioma.

- Coordinadora. Sin saber si vas a encontrar trabajo o no. A mí me parece muy duro imaginarme que estoy emigrando de mi país, que estoy haciéndolo de manera ilegal, que cuando estoy haciéndolo, de repente me encuentro con un montón de cadáveres, iuf!, se me hace insoportable de imaginar solamente. No alcanzo a imaginar la gente que lo pueda vivir, cómo pueda ser eso. Se me hace de una dureza extrema.

En este caso, al releer la coordinadora del club de lectura un fragmento del libro, se está ofreciendo a los niños la posibilidad de repensar ese pasaje. En la conversación mantenida entre el alumno que pide la palabra y la coordinadora surgen ideas y matices que el grupo siguió con atención, estimulando su pensamiento sobre las dificultades por las que atraviesan las personas inmigrantes para venir a España.

\section{Conclusiones}

Todos estos breves ejemplos constituyen pequeñas muestras de debates más amplios producidos en los encuentros regulares mensuales de un club de lectura escolar, donde se liga el estímulo del hábito lector y la formación ciudadana. Dar la opinión sobre una lectura y debatir sobre algunos de sus momentos no sólo contribuye a impulsar el hábito lector, sino a desarrollar el pensamiento divergente y el espíritu crítico. Sánchez y Yubero (2004, p. 91), entre otros, consideran que "al hablar de la lectura debemos señalar el fortalecimiento de un espíritu crítico capaz de rechazar normas y valores sin sentido.”. 
En este proceso es muy importante destacar la relevancia de la formación del profesorado: en cuestiones de animación a la lectura, educación en valores y metodologías dialógicas, para promover el desarrollo de la competencia lingüística, literaria, lectora y axiológica de los estudiantes. En las preguntas que formula un coordinador de club de lectura escolar con niños es posible observar si está formado y si sabe lo que busca. Además, la competencia del profesorado en la materia también es imprescindible en la elaboración de los Planes Lectores de Centro y el desarrollo del curriculum en el área de Lengua Castellana en las aulas.

Desde el punto de vista lingüístico-literario, una tertulia literaria dialógica en el marco de un club de lectura escolar con niños de Educación Primaria permite acercar al alumnado una actividad de ocio novedosa en muchos casos como es la lectura, lo cual tiene mucho valor cuando los estudiantes están privados de un ambiente intelectual motivador por razones socio-culturales, como sucedía en el caso analizado. Por otra parte, es una actividad que incide en la mejora de la competencia literaria de los niños y les acerca a obras seleccionadas por un mediador que conoce los textos más adecuados para estimular en el niño la capacidad crítica y la valoración estética de los textos literarios.

Desde el punto de vista educativo-axiológico, los coordinadores pueden conocer mejor cómo piensan los alumnos y cómo interpretan los relatos, con una mirada infantil, pueden introducir temáticas que estimen oportunas y hablar de ellas con naturalidad, pueden generar momentos de conversación sobre asuntos complejos en un medio reflexivo, en un contexto de interrogación, que no de interrogatorio, apoyando el proceso de construcción racional y autónoma de valores en los niños.

Los estudiantes, además, a raíz de las lecturas y las reuniones realizadas para comentarlas, pueden ponerse en el lugar de los personajes de las historias fantásticas, pueden criticar una lectura o una parte de la misma con argumentos. Como plantea Jurado (2008, 90), “desde la escuela se pueden formar lectores críticos y no sólo lectores alfabetizados. Esta distinción es de gran importancia: una cosa es educar en la escuela para alfabetizar y otra orientar desde la escuela para saber leer críticamente los textos de la cultura. Desafortunadamente la escuela, con la excepción de las escuelas innovadoras, tiende hacia la alfabetización”. Un club de lectura escolar puede (y debe) poner la lectura al servicio de fines formativos y no sólo instructivos.

\section{Referencias bibliográficas}

ABRIL, M. (2000). Lectura y valores. Puertas a la lectura, 9-10, 8-12.

ÁLVAREZ, C. (2010). Un club de lectura para mayores y pequeños. Cuadernos de Pedagogía, 402, 28-30.

ÁLVAREZ, C. (2011). La animación a la lectura en la Educación Primaria: una innovación posible. Abareque: Revista digital de bibliotecas escolares de la Consejería de Educación del Principado de Asturias, 3. Puede descargarse en: http://web.educastur.princast.es/proyectos/abareque/[Consultado: 21-1-12]. 
ÁLVAREZ, C. \& SAN FABIÁN, J. L. (2012). La elección del estudio de caso en la investigación cualitativa. Gazeta de Antropología, 28/1. Puede descargarse en: http://www.ugr.es/ pwlac/G28_14Carmen_Alvarez-JoseLuis_SanFabian.pdf [Consultado: 10-7-12].

ARANDA, J. \& GALINDO, B. (2009). Leer y conversar. Una introducción a los clubs de lectura. Gijón: Trea.

ATWELL, N. (2007). The reading zone: how to help kids become skilled, passionate, habitual, critical readers. New York: Scholastic.

BARTOLOMÉ, B. (1999). Las bibliotecas escolares infantiles como iniciación a la lectura. Revista complutense de educación, 10 (2) 13-27.

BLUM, I. H., KOSKINEN, P. S., BHARTIYA, P. \& HLUBOKY, S. (2010). Thinking and talking about books: using prompts to stimulate discussion. Thereadingteacher, 63 (6) 495-499.

BOLÍVAR, A. (2007). Educación para la ciudadanía. Algo más que una asignatura. Barcelona: Graó.

BUXARRAIS, M. R. (1997). La formación del profesorado en educación en valores. Propuesta y materiales. Bilbao: Desclée de Brouwer.

BUXARRAIS, M. R., MARTINEZ, M., PUIG, J. M. \& TRILlA, J. (1995). La educación moral en Primaria y Secundaria. Madrid: MEC-Edelvives.

CALVO, B. (2007). Los clubs de lectura en España. Peonza, 68, 21-29.

CAMPS, V., GARCÍA J., GIL, R. \& RUIZ, J. I. (1998). Educar en valores: un reto educativo actual. Bilbao: ICE-Universidad de Deusto.

CAMPS, V. (2011). El gobierno de las emociones. Barcelona: Herder.

CARR, W. (2007). El docente investigador en educación. México: Universidad de Ciencias y Artes de Chiapas.

CARRATALÁ, F. (2008). Motivación y desmotivación ante la lectura. CDL Madrid, 193, 11-16.

CASSANY, D. (2002). Aproximaciones a la lectura crítica: teoría, ejemplos y reflexiones. Tarbiya. Revista de investigación e innovación educativa, 32, 113-132.

CASSANY, D. (2008). Llegir críticament, all largdel currículum. Presentació. Tempsd'Educació, 34, 7-10.

CERRILLO, P. (2005). La animación a la lectura desde edades tempranas. Idea La Mancha, 1, 99-106.

CERRILLO, P. (2007). Literatura infantil y juvenil y educación literaria. Barcelona: Octaedro.

CERRILLO, P. \& GARCÍA PADRINO, J. (1996). Hábitos lectores y animación a la lectura. Cuenca: Ediciones de la Universidad de Castilla la Mancha.

CHAMBERS, A. (2007). Dime. México: FCE.

CORONAS, M. (2005). Animación y promoción lectora en la escuela. Revista de Educación, 1, 339-355.

DOMINGO G. \& SOLA, M. A. (2005). Els clubs de lectura: dues experiències a dues ciutats. Item: Revista de Biblioteconomía y Documentación, 40, 29-44.

DURBAN, G. (2010). La biblioteca escolar, hoy. Un recurso estratégico para el centro. Barcelona: Graó. 
ELLIOT, J. (1993). El cambio educativo desde la investigación-acción. Madrid: Morata.

ESCÁMEZ, J. (2003). Pensar y hacer hoy educación moral. Teoría de la educación. Revista Interuniversitaria, 15, 21-31.

FERNÁNDEZ PAZ, A. (1996). Luna de Senegal. Madrid: Anaya.

GARCÍA PADRINO, J. (2005). La promoción de la lectura: una permanente tarea educativa. Revista de Educación, número extraordinario, 37-51.

GUTIÉRREZ, R. \& RODRÍGUEZ, B. (2008). Aproximaciones y propuestas para una didáctica de los valores a través de las lecturas literarias. En Tejerina, I. (Coord.) Leer la interculturalidad: una propuesta didáctica para la ESO desde la narrativa, el álbum y el teatro. Cantabria. Universidad de Cantabria-Gobierno de Cantabria.

JURADO, F. (2008). La formación de lectores críticos desde el aula. Revista Iberoamericana de Educación, 46, 89-105.

KEMMIS, S. (1992). Cómo planificar la investigación-acción. Barcelona: Laertes.

LAGE, J. J. (2006). Animar a leer desde la biblioteca. Madrid: CCS.

LYNCH, J. (2009). Print literacy engagement of parents from low-income backgrounds. Implications for adult and family literacy programs. Journal of adolescent and adult literacy, 52 (6) 509- 521.

LOCKWOOD, M. (2008). Promoting reading for pleasure in the Primary School. UnitedKingdom: Paul Chapman Publishing.

LOUZAO, M. (2011). La comunidad educativa ante la interculturalidad. Aproximación al estudio de la percepción de la misma en una escuela asturiana. Cultura y educación, 23 (4) 575-588.

LOZANO CARBAYO, P. (2005). ¡No es tan fácil ser niño! Madrid: Edebé.

MANTILLA, L. (2009). Animando a leer. Técnicas para estimular la afición por la lectura. Sevilla: Eduforma.

MARTÍNEZ, M. Y HOYOS, G. (Coord.) (2006). La formación en valores en las sociedades democráticas. Barcelona: Octaedro.

MARTOS, E. \& RÖSING, T. (Coords.) (2009). Prácticas de lectura y escritura. Passo Fundo: Editora Universitária da Universidade de Passo Fundo.

MATA, J. (2009). Animación a la lectura. Hacer de la lectura una práctica feliz, trascendente y deseable. Barcelona: Graó.

MEYER, K. E. (2010). A collaborative approach to reading workshop in the middle years. Thereadingteacher, 63 (6) 501-507.

NAVARRO, G. (2000). El diálogo. Procedimiento para la educación en valores. Bilbao: Desclée de Brouwer.

OSTRIA, M. (2005). Enseñar/Aprender a leer. En Catedra UNESCO para la lectura y la escritura. Puede descargarse en:

http://www2.udec.cl/catedraunesco/06OSTRIA.pdf. [Consultado: 20-4-11].

PATTE, G. (2008). Déjenlos leer. Los niños y las bibliotecas. México: FCE.

PENNAC, D. (1993). Como una novela. Barcelona: Anagrama.

PEÑA, J. \& BARBOZA, F. D. (2002). La familia en un club de lectura escolar para favorecer la adquisición y desarrollo de la lengua escrita. Educere: Revista venezolana de educación, 6 (18) 168-175. 
PUIG ROVIRA, J. M. (1995). Construcción dialógica de la personalidad moral. En Revista Iberoamericana de Educación, 8, 103-120.

SÁNCHEZ, S. \& YUBERO, S. (2004). La transmisión y recepción de valores desde la lectura. Un estudio con niños de educación primaria. En S. Yubero, E. Larrañaga y P. C. Cerrillo. Valores y lectura. Estudios multidisciplinares (89-129). Castilla La Mancha: Universidad de CastillaLa Mancha.

SENÍS, J. (2006). Valores y lectura(s). Ocnos, 2, 79-90.

STENHOUSE, L. (1987). La investigación como base de la enseñanza. Madrid: Morata.

TEJERINA, I. (1997). Literatura infantil y formación de un nuevo maestro. En Monge, J. J. \& Portillo, R. La formación del profesorado desde una perspectiva interdisciplinar: retos ante el siglo XXI. Santander: Universidad de Cantabria.

TEJERINA, I. (2008). Coordenadas teóricas y contextuales de la educación literaria ante el desafío intercultural. En Tejerina, I. (Coord.) Leer la interculturalidad: una propuesta didáctica para la ESO desde la narrativa, el álbum y el teatro (275-293). Cantabria: Universidad de Cantabria-Gobierno de Cantabria.

WHITEHEAD, J. (2009). Generating living theory and understanding in action research studies. Actionresearch, 7 (1) 85- 99.

YUBERO, S. \&Larrañaga, E. (2010). El valor de la lectura en relación con el comportamiento lector. Un estudio sobre los hábitos lectores y el estilo de vida en niños. Revista OCNOS, 6,7-20.

\section{Correspondencia con las autoras:}

Carmen ÁLVAREZ ÁLVAREZ

Universidad de Cantabria

carmen.alvarez@unican.es

Facultad de Educación

Edificio Interfacultativo, despacho 309,

Avenida de los Castros, 39005

Santander, Cantabria

Teléfono: 942201266

Raquel GUTIÉRREZ SEBASTIÁN

Universidad de Cantabria

gsebastianr@unican.es

Departamento de Filología

Facultad de Educación

Edificio Interfacultativo, despacho 246

Avenida de los Castros, 39005

Santander, Cantabria

Teléfono: 942201141 